\title{
Peranan Penyuluh Pertanian Lapangan (PPL) sebagai Fasilitator Usahatani Petani di Subak Empas Buahan Kecamatan Tabanan Kabupaten Tabanan
}

\author{
NI PUTU ISTRI PADMASWARI, NYOMAN SUTJIPTA, \\ I GEDE SETIAWAN ADI PUTRA
}

\author{
Program Studi Agribisnis, Fakultas Pertanian, Universitas Udayana \\ J1. PB. Sudirman Denpasar 80323 \\ Email: padmaswari@yahoo.co.id \\ nsutjipta@yahoo.com
}

\begin{abstract}
The Role of Agricultural Field Extension (PPL) as a Facilitator of Farmers Farming in Subak Empas Buahan Tabanan Subdistrict, Tabanan Regency
\end{abstract}

Agricultural extension workers are people who work in extension activities by communicating on target extension, so that the target was able to make the decisionmaking process correctly.Extension activities in agricultural development act as a bridge between the theory to practice run by the farmers with the aim of adding education and innovation of new farmers to a better and advanced agriculture. The purpose of this study is to know how the role of agricultural field extension (PPL) as a facilitator farmers farming in Subak Empas Buahan, District Tabanan.The results of the study showed that the role of extension (PPL) in facilitating the needs of farmers as educators, mediators, motivators, an evaluators. Based on the overall results of respondent's responses the role of extension workers as educators obtained average score achievement of 3,94 are categorized good. Result of mediator role answer that is with average score 3,99with good category. Result of motivator role answer that is with achievement of average score obtained that is 4,10 with good category. Obtained the result of answers from the role of the evaluator is with the achievement of an average score of 3,92 with good category.

Keywords: Role, extension workers, farmer facilitators, farmers

\section{Pendahuluan}

\subsection{Latar Belakang}

Peran adalah suatu konsep perihal apa yang dapat di lakukan individu yang penting bagi struktur sosial masyarakat, peran meliputi norma-norma yang dikembangkan dengan posisi atau tempat seseorang dalam masyarakat. Peran yang di tekankan adalah semua pihak terkait di dalam sektor pertanian, karena pertanian sebagai leading sektor yang merupakan tulang punggung pembangunan Indonesia (Nurmayanti,2010).

Berdasarkan Perda Provinsi Bali No. 9 tahun 2012, subak merupakan organisasi tradisional di bidang tata guna air dan tata pola tanam di tingkat usaha tani pada masyarakat adat Bali yang bersifat sosioagraris, religius, serta ekonomis yang 
secara historis terus tumbuh dan berkembang serta berproduksi secara periodik. Keterlibatan fasilitator pembangunan yang memiliki kemampuan komunikasi yang sepadan merupakan salah satu kunci keberhasilan proses diseminasi dan alih teknologi pertanian.Tujuan penyuluh pertanian yaitu mengembangkan sistem pertanian yang berkelanjutan, dalam upaya mewujudkan tujuan tersebut diperlukan upaya untuk meningkatkan kualitas sumberdaya manusia yang berguna dalam menunjang pembangunan pertanian. Penyuluh sebagai fasilitator usahatani yang bertugas memfasilitasi petani yaitu perannya sebagai edukator, mediator, motivator dan evaluator lebih diupayakan melalui program penyuluhan, agar petani meningkatkan minatnya dibidang pertanian. Berdasarkan hal tersebut, jelaslah bahwa untuk mensukseskan pembangunan dibidang pertaniankhususnya di Subak Empas Buahan, Kecamatan Tabanan, Kabupaten Tabanan tidak terlepas dari peranan seorang penyuluh sebagai fasilitator, yang mana dapat memberikan kontribusi bagi petani dalam hal menyelesaikan permasalahan dibidang pertanian kearah yang lebih baik serta mampu mengatasi kendala-kendala yang dihadapi petani dilapangan. Perubahan minat petani dalam proses peningkatan edukasi serta penyaluran inovasi mampu memberi responpositif terhadap pola pikir petani, yang kemudian menjadi tujuan terpenting dalam proses peningkatan produktivitas usahatani.

\subsection{Rumusan Masalah}

Berdasarkan latar belakang masalah yang telah dikemukakan diatas maka rumusan masalah yang akan dibahas dalam penelitian ini, yaitu bagaimana peranan penyuluh pertanian lapangan (PPL) sebagai fasilitator usahatani petani di Subak Empas Buahan, Kecamatan Tabanan, Kabupaten Tabanan.

\subsection{Tujuan Penelitian}

Berdasarkan rumusan masalah penelitian yang telah dikemukakan diatas, maka tujuan penelitian ini untuk mengetahui peranan penyuluh pertanian lapangan (PPL) sebagai fasilitator usahatani di Subak Empas Buahan, Kecamatan Tabanan, Kabupaten Tabanan.

\section{Metodologi Penelitian}

\subsection{Lokasi dan Waktu Penelitian}

Penelitian ini berlokasi di Subak Empas Buahan Kecamatan Tabanan, Kabupaten Tabanan. Pemilihan kawasan ini sebagai lokasi penelitian dilakukan secara sengaja (purposive) yang didasarkan atas beberapa pertimbangan. Waktu pengumpulan data dilakukan mulai November s.d Juli 2017, yaitu terhitung mulai dari peneliti mengumpulkan data sekunder dalam menunjang pengisian data proposal hingga mengumpulkan data dari responden-responden yang ada di lokasi penelitian yaitu Subak Empas Buahan. 


\subsection{Jenis dan Sumber Data}

Penelitian ini menggunakan dua jenis data yang meliputi data kuantitatif dan data kualitatif.Sumber data terdiri daridata primer dan data sekunder.

\subsection{Teknik Pengumpulan Data}

Metode yang digunakan dalam mengumpulkan data yaitu teknik dari hasil observasi, wawancara, dokumentasi.

\subsection{Instrumen Pengumpulan Data}

1. Kuesioner

Alat ukur instrument yang digunakan dalam penelitian ini adalah uji validitas dan uji reliabilitas. Uji validitas adalah bukti bahwa instrument, teknik, atau proses yang digunakan untuk mengukur konsep yang dimaksudkan (Sarjono dan Julianita, 2011). Perhitungan koefisien korelasi product moment menggunakan bantuan software SPSS. Penelitian ini juga menggunakan pengujian reliabilitas instrument penelitian dengan ukuran alat ukur internal consistency yaitu dengan koefisien Alpha Cronboach.

2. Pedoman Wawancara

Pedoman wawancara adalah merupakan suatu panduan yang dibuat sebelum melakukan wawancara terhadap responden, yang berisikan pemilihan kriteria responden serta hal-hal apa saja yang perlu digali dari responden agar semua data yang diperlukan dapat diperoleh.

\subsection{Populasi, Sampel, dan Teknik Sampling}

Populasi dalam penelitian ini adalah seluruh petani Subak Empas Buahan yang mengikuti penyuluhan dari PPL serta yang menjalankan program penyuluhan.Petani Subak Empas Buahan tercatat memiliki jumlah anggota subak dengan 318 orang anggota. Pengambilan sampel dengan menggunakan teknik purposive sampling yaitu teknik penentuan sampel berdasarkan pertimbangan tertentu yaitu berdasarkan tujuan penelitian. Jumlah sampel yang diambil penulis dan penentuansampel responden pada penelitian ini adalah 80 orang responden.

\subsection{Variabel Penelitian dan Pengukuran}

Variabel yang diteliti dalam penelitian ini adalah peranan penyuluh pertanian lapangan (PPL) sebagai fasilitator usahatani petani, mengenai konsep, indikator, variabel, dan skala pengukuran. Skala pengukuran yang digunakan dalam penelitian ini adalah skala ordinal 1-5, skor dengan nilai 1 merupakan skor minimum dan skor nilai 5 merupakan skor maksimum.

\subsection{Batasan Operasional Variabel}

Penelitian ini memiliki batasanan operasional variabel, dengan tujuan agar tidak menyimpang dari pokok permasalahan, dengan demikian diberikan batasan- 
batasan mengenai peranan penyuluh pertanian lapangan (PPL) di Subak Empas Buahan, peranan fasilitator, edukator, mediator, motivator, dan evaluator.

\subsection{Analisis Data}

Metode analisis data yang digunakan terhadap data yang diperoleh dalam penelitian ini adalah menggunakan analisis data secara deskriptifkualitatif dan korelasi Rank Spearman. Korelasi Rank Spearman adalah alat uji statistik yang digunakan untuk menguji hipotesis asosiatif dua variabel bila datanya berskala ordinal (rangking). Analisis deskriptif kualitatif bertujuan untuk menjabarkan secara jelas dan sistematis data yang didapat. Data yang diperoleh kemudian didistribusikan kedalam bentuk tabel dan dihitung frekuensi serta presentasinya dengan bantuan skoring menggunakan skala ordinal (skala lima). Rentang keberhasilan akan dihitung dengan skor 1,2,3,4,5. Sudarmawan (2010) mengemukakan bahwa, data hasil pengukuran akan didistribusikan kedalam kelas-kelas yang sudah ditentukan dengan rumus interval kelas.

\section{Hasil dan Pembahasan}

\subsection{Karakteristik Responden}

Karakteristik responden berdasarkan pendidikan merupakan jumlah tahun mengikuti pendidikan formal yang ditempuh petani pada bangku sekolah. Pendidikan akan berpengaruh terhadap perilaku dan tingkat adopsi suatu inovasi. Pencapaian hasil karakteristik responden disajikan pada tabel 1 dibawah ini.

\section{Tabel 1.}

Distribusi Responden Berdasarkan Karakteristik Subak Empas Buahan Kecamatan Tabanan, Tahun 2017

\begin{tabular}{lllcc}
\hline No Karakteristik responden & \multicolumn{1}{c}{ Kategori } & Orang & $\%$ \\
\hline 1 & Umur & Sedang $(>51-59)$ & 23 & 28,75 \\
2 & Pendidikan & Sangat rendah $(6-7,2)$ & 66 & 82,5 \\
3 & Luas lahan & Sedang $(>48,8-69,2)$ & 21 & 26,25 \\
4 & Hasil panen & Sedang $(>8.300-12.200)$ & 28 & 35 \\
\hline
\end{tabular}

Sumber: Analisis Data Primer, 2017

\subsection{Peranan Penyuluh Pertanian Lapangan (PPL) Sebagai Fasilitator}

Penelitian ini mengenai peranan penyuluh pertanian lapangan (PPL) pada Subak Empas Buahan Kecamatan Tabanan, Kabupaten Tabanan.Keberhasilan kegiatan penyuluhan tentunya tidak terlepas dari peran para PPL. Peran PPL yang dimaksud adalah sebagai edukator, sebagai motivator, sebagai mediator, dan sebagai evaluator. Pencapaian hasil dari lebih masing-masing peranan tersebut bisa dilihat pada tabel 2 dibawah ini. 
Tabel 2.

Distribusi Responden berdasarkan Peranan Penyuluh Pertanian Lapangan (PPL) sebagai Fasilitator di Subak Empas Buahan Kecamatan Tabanan, Tahun 2017

\begin{tabular}{llcc}
\hline No & Indikator & $\begin{array}{c}\text { Pencapaian skor } \\
\text { rata - rata }\end{array}$ & Kategori \\
\hline 1 & Edukator & 3,94 & Baik \\
2 & Mediator & 3,99 & Baik \\
3 & Motivator & 4,10 & Baik \\
4 & Evaluator & 3,92 & Baik \\
\hline Peranan Penyuluh & $\mathbf{3 , 9 9}$ & Baik \\
\hline
\end{tabular}

Sumber:Analisis Data Primer, 2017

\subsubsection{Edukator}

Berdasarkan hasil keseluruhan jawaban responden diperoleh pencapaian skor rata-rata 3,94 dengan yang dikategorikan baik. Peranan PPL sebagai edukator diartikan sebagai kemampuan penyuluh dalam memberikan pelayanan kepada petani dalam setiap kegiatan berusahatani yang merupakan program penyuluhan oleh PPL. Peran penyuluh dalam kegiatan ini harus mampu mengedukasi petani, bertugas mendidik, dan mampu mengatasi permasalahan yang dihadapi petani. Hasil tersebut dapat dikatakan minat petani dalam menjalankan program penyuluhan perlu dioptimalkan, sehingga dalam program penyuluhan berjalan sesuai sasaran dan harapan petani dalam upaya mengembangkan keterampilan petani.

\subsubsection{Mediator}

Berdasarkan kuisioner yang diberikan kepada setiap respnden dapat diperoleh hasil dari jawaban dari peranan mediator yaitu dengan rata-rata skor 3,99 dengan kategori baik. Peranan penyuluh sebagai mediator merupakan kemampuan penyuluh dalam memberikan informasi dan menghubungkan petani dengan sumber informasi guna memecahkan masalah yang dihadapi dalam program yang dijalankan penyuluh. Pengadaan bantuan kebutuhan petani perlu ditingkatkan, dengan demikian dari pernyataan tersebut petani Subak Empas Buahan menyatakan dalam memfasilitasi kebutuhan petani masih tergolong rendah.

\subsubsection{Motivator}

Perolehan hasil jawaban peranan motivator yaitu dengan pencapaian rata-rata skor yang diperoleh yaitu 4,10 dengan pada kategori sangat baik. Indikator ini diajukan sepuluh pernyataan/pertanyaan untuk mengukur bagaimana peranan penyuluh pertanian lapangan (PPL) sebagai motivator yang mana peranan PPL sebagai motivator yaitu memiliki kemampuan penyuluh dalam memberikan dorongan pada petani melalui berbagai macam upaya agar petani tergerak berpartisipasi dalam program penyuluhan pertanian lapangan (PPL). Berdasarkan hal 
tersebut, peranan penyuluh dalam memotivasi petani untuk menjalankan program penyuluhan dilakukan petani yang secara rutin untuk terjun kelapangan memberikan dorongan, serta motivasi untuk mengatasi permasalahan petani dengan demikian penilaian petani dalam hal tersebut tergolong baik.

\subsubsection{Evaluator}

Hasil dari jawaban responden mengenai peranan evaluator yaitu dengan pencapaian skor rata-rata 3,92 dengan kategori baik. Variabel ini diajukan sepuluh pernyataan atau pertanyaan untuk mengukur bagaimana peranan penyuluh pertanian lapangan (PPL) sebagai evaluator. Hal tersebut menunjukan bahwa peranan penyuluh sebagai evaluator tergolong sangat baik disebabkan kinerja penyuluh dalam proses pengevaluasi, PPL senantiasa terjun kelapangan mengatasi persoalan yang dihadapi petani serta mengevaluasi program penyuluhan untuk peningkatan kualitas program.

\subsection{Produktivitas Usahatani}

Variabel ini diajukan dua pernyataan atau pertanyaan untuk mengukur bagaimana produktivitas usahatani petani di Subak Empas Buahan. Faktor-faktor produksi yang mempengaruhi produktivitas usahatani mencakup luas lahan dan produksi hasil panen yang dihasilkan oleh petani Subak Empas Buahan Kecamatan Tabanan, Kabupaten Tabanan tersaji pada tabel 2.

Berdasarkan tabel 2 dapat diperoleh hasil pencapaian skor rata-rata 2,89 hal ini menunjukan bahwa minat petani dalam menjalankan program penyuluhan serta minat masyarakat usia muda perlu ditingkatkan. Lahan bercocok tanam memerlukan cara-cara pengelolaan yang tepat dan benar agar dapat menunjang pendapatan usahatani yang tinggi dan lebih banyak dengan kualitas yang lebih baik.

\subsection{Hubungan Peranan Penyuluh dan Produktivitas Usahatani}

Hasil uji pada penelitian ini menunjukan terjadi hubungan antara peranan penyuluh pertanian lapangan (PPL) sebagai fasilitator di Subak Empas Buahan terhadap produktivitas usahatani. Hasil uji Koelasi Rank Spearman disajikan pada tabel 3 dibawah ini. 
Tabel 3.

Hubungan Peranan Penyuluh Pertanian Lapangan (PPL) sebagai Fasilitator Usahatani Petani di Subak Empas Buahan Kecamatan Tabanan

Kabupaten Tabanan, Tahun 2017

\begin{tabular}{llcc}
\hline No $\quad$ Korelasi & Rs & Sig & Keterangan \\
\hline $\begin{array}{l}\text { 1. Hubungan antara peranan PPL } \\
\text { sebagai edukator } \\
\text { terhadap produktivitasusahatani }\end{array}$ & $0,445^{* *} 0,000$ & $\mathrm{SS}$ \\
$\begin{array}{l}\text { 2. } \begin{array}{l}\text { Hubungan antara peranan PPL } \\
\text { sebagai mediator } \\
\text { terhadap produktivitas usahatani }\end{array} \\
\begin{array}{l}\text { Hubungan antara peranan PPL } \\
\text { sebagai motivator }\end{array}\end{array}$ & $0,444 * * 0,000$ & $\mathrm{SS}$ \\
$\quad \begin{array}{l}\text { terhadap produktivitas usahatani } \\
\text { Hubungan antara peranan PPL } \\
\text { sebagai evaluator } \\
\text { terhadap produktivitas usahatani }\end{array}$ & $0,545^{* *} 0,000$ & $\mathrm{SS}$ \\
\hline
\end{tabular}

Sumber:Analisis Data Primer, 2017

Keterangan

SS $\left({ }^{* *}\right) \quad$ : Sangat signifikan dengan tingkat kepercayaan $\alpha=0,01$

$S\left(^{*}\right) \quad$ : Signifikan dengan tingkat kepercayaan $\alpha=0,05$

NS : : Tingkat signifikan/non signifikan

Berdasarkan tabel 3 diatas dapat dinyatakan bahwa hubungan peranan penyuluh pertanian sebagai fasilitator yaitu memfasilitasi petani, memiliki peranan penting terhadap produktivitas usahatani petani. Hubungan dari masing-masing indikator peranan penyuluh sebagai edukator, mediator, motivator dan evaluator dihubungkan dengan mengkorelasikan nilai koefisien korelasi dannilai signifikansinya pada produktivitas usahatani petani.

\subsubsection{Hubungan peranan penyuluh sebagai edukator dan produktivitas usahatani}

Hasil analisis Rank Spearman pada tabel 3diketahui bahwa hubungan antara peran penyuluh sebagai edukator terhadap produktivitas usahatani petani memiliki hubungan yang sangat signifikan dengan nilai koefisien korelasinya sebesar 0,455 dengan besar signifikansi $0,000<0,01$. Hubungan antara peranan PPL sebagai edukator memiliki korelasi yang cukup kuat atau berada pada kisaran $(>0,25-0,5)$.

\subsubsection{Hubungan peranan penyuluh sebagai mediator dan produktivitas usahatani}

Berdasarkan tabel 3 dapat diketahui bahwa peranan penyuluh pertanian lapangan (PPL) sebagai mediator terhadap produktivitas usahatani memiliki hubungan yang sangat signifikan dengan nilai koefisien korelasinya 0,444 dengan besar signifikan $0,000<0,01$. Hubungan antara peranan penyuluh sebagai mediator 
dengan produktivitas usahatani petani dapat diartikan bahwa memiliki korelasi yang cukup kuat atau berada pada kisaran $(>0,25-0,5)$.

\subsubsection{Hubungan peranan penyuluh sebagai motivator dan produktivitas usahatani}

Berdasarkan tabel 3 dapat diketahui bahwa peranan penyuluh pertanian lapangan (PPL) sebagai mediator terhadap produktivitas usahatani memiliki hubungan yang sangat signifikan dengan nilai koefisien korelasinya 0,444 dengan besar signifikan $0,000<0,01$. Hubungan antara peranan penyuluh sebagai mediator dengan produktivitas usahatani petani menyatakan bahwa memiliki korelasi yang cukup kuat atau berada pada kisaran $(>0,25-0,5)$.

\subsubsection{Hubungan peranan penyuluh sebagai evaluator dan produktivitas usahatani}

Berdasarkan tabel 3 dapat diketahui bahwa peranan penyuluh pertanian lapangan (PPL) sebagai evaluator terhadap produktivitas usahatani memiliki hubungan yang sangat signifikan dengan nilai koefisien korelasinya 0,462 dengan besar signifikan $0,000<0,01$. Hubungan antara peranan penyuluh sebagai mediator dengan produktivitas usahatani petani memiliki korelasi yang cukup kuat atau berada pada kisaran $(>0,25-0,5)$.

\section{Simpulan dan Saran}

\subsection{Simpulan}

Hasil keseluruhan jawaban responden diperoleh pencapaian skor rata-rata 3,94 yang memiliki kategori baik.Peranan penyuluh pertanian lapangan (PPL) yang memiliki tugas sebagai mediator, hasil keseluruhan jawaban responden diperoleh pencapaian skor rata-rata 3,99 dengan kategori baik. Peranan penyuluh pertanian lapangan (PPL) yang memiliki tugas sebagai motivator, hasil keseluruan jawaban responden diperoleh pencapaian skor rata-rata 4,10 dengan dikategorikan baik. Peranan penyuluh pertanian lapangan (PPL) yang memiliki tugas sebagai evaluator, hasil keseluruhan jawaban responden diperoleh pencapaian skor rata-rata 3,92 dengan kategori baik.

\subsection{Saran}

Berdasarkan hasil penelitian adapun saran yang dapat disampaikan peneliti bahwa tingkat peranan penyuluh di Subak Empas Buahan menghasilkan skor yang tergolong paling rendah. Berdasarkan hal tersebut saran yang dapat disampaikan peneliti adalah, dengan peningkatan kapasitas evaluasi yang dilakukan penyuluh mengenai program yang telah jalan maupun tidak jalan mampu dijadikan suatu kajian dalam proses pengevaluasian agar nantinya suatu program penyuluhan bermanfaat bagi petani. Tujuan penyuluhan dapat berjalan sesuai sasaran, sehingga upaya meningkatkan kreativitas petani dalam berusahatani menghasilkan dampak positif dalam peningkatan produktivitas usahatani padi. 


\section{Ucapan Terimakasih}

Terima kasih kepada semua pihak yang telah membantu penyusunan karya ilmiah ini sampai e-jurnal ini dapat diterbitkan.

\section{Daftar Pustaka}

Anwas. 1992. Pengertian Petani. (Artikel Online). Tersedia di (http://repository.usu.ac.id/bitstream/123456789/57216/4/Chapter\%20IIdf). Diakses pada tanggal 10 November 2016.

Arikunto, Suharsimi. 2002. Prosedur Penelitian. PT. Rineka Cipta. Jakarta.

Arikunto, Suharsimi. 2006. Prosedur Penelitian: Suatu Pendekatan Praktek. Edisi Revisi. PT. Rineka Cipta. Jakartan.

Antara, I, Made. 2010. Bahan Ajar Metodelogi Penelitian Sosek Program Studi UNUD. Denpasar.

Nurmayanti. 2010. Pengertian Peran. (Artikel Online). Tersedian di (http://abstrak.ta.uns.ac.id?wisuda?upload?H0812166_bab2.pdf). Diakses pada tanggal 10 Maret 2017

Sarjono, Haryadi dan Winda Julianita.2011. SPSS vs LISREL: Sebuah Pengantar, Aplikasi untuk Riset. Salemba Empat. Jakarta.

Sevilla, Consuelo et, Al. 1993. Pengantar Metode Penelitian. Universitas Indonesia Press. Jakarta.

Sudibyo. 2010. Pengertian Analisis Data. (Artikel Online). Tersedia di (http://pensasb.info/wp-content/uploads/2010/10/ANALISIS-DATA

DALAM STATISTIK.pdf). Diakses pada tanggal 23 Februari 2017.

Sugiyono. 2003.Metode Penelitian Kuantitatif Kualitatif dan $R \& D$. AlfaBeta.Bandung.

Sugiyono. 2009. Metode Penelitian Bisnis (Pendekatan Kualitatif, Kuantitatif dan $R \& D)$. Bandung: Alfa Beta.

Sugiarto, Dkk.2001.Teknik Sampling. Gramedia Pusaka Utama. Jakarta.

Sutopo, H B. 2002. Metodologi Penelitian Kualitatif (Dasar Teori dan Terapannya dalam Penelitian).Sebelas Maret University Press.Surakarta.

Suhardiyono. 2012.Metode Penelitian Kuantitatif, Kualitatif dan $R \& D$. Cetakan ke17. Bandung: Alfa Beta. 